\title{
Narrative Review of Carotid disease and the kidney
}

\author{
Luca Zanoli $^{1} \wedge$, Dimitri P. Mikhailidis ${ }^{2}$ \\ ${ }^{1}$ Nephrology, Department of Clinical and Experimental Medicine, University of Catania, Catania, Italy; ${ }^{2}$ Department of Clinical Biochemistry, Royal \\ Free Hospital campus, University College London, London, UK \\ Contributions: (I) Conception and design: Both authors; (II) Administrative support: Both authors; (III) Provision of study materials or patients: \\ Both authors; (IV) Collection and assembly of data: Both authors; (V) Data analysis and interpretation: Both authors; (VI) Manuscript writing: Both \\ authors; (VII) Final approval of manuscript: Both authors. \\ Correspondence to: Luca Zanoli, MD, PhD, FASN. Nephrology, Department of Clinical and Experimental Medicine, Policlinico Universitario, \\ University of Catania, Via Santa Sofia 78, 95123 Catania, Italy. Email: luca.zanoli@unict.it.
}

\begin{abstract}
Patients with chronic kidney disease (CKD) have an increased cardiovascular (CV) risk that is only in part explained by established risk factors. Carotid arteriosclerosis and atherosclerosis are increased in $\mathrm{CKD}$, play a role in the causation of $\mathrm{CV}$ disease in these patients and can affect the progression of renal disease. The arterial stiffening process is evident even in CKD patients with a very mild reduction of glomerular filtration rate (GFR) whereas arterial thickening is evident in more advanced stages. Possible mechanisms include functional and structural alterations of the arterial wall. Arterial stiffness can mediate the effect of CKD on target organs (i.e., brain, kidney and heart). In this review we discuss the arterial phenotype of patients with CKD. This is characterized by increased common carotid artery stiffness and outward remodeling (enlargement and thickening of the arterial wall) and a normal/reduced stiffness paired with an inward remodeling (narrowing of the arterial wall) of muscular arteries. We also discuss the consequences of carotid dysfunction, including the involvement of large elastic arteries stiffness on ventricular-vascular coupling, the mechanisms linking carotid stiffening and increased cardio- and cerebrovascular risk in CKD patients, and the therapeutic options to improve carotid function.
\end{abstract}

Keywords: Arterial stiffness; carotid artery; chronic kidney disease (CKD); inflammation; pulse wave velocity

Submitted Jun 29, 2020. Accepted for publication Sep 09, 2020.

doi: 10.21037/atm-20-5001

View this article at: http://dx.doi.org/10.21037/atm-20-5001

\section{Introduction}

Cardiovascular (CV) risk is higher in patients with chronic kidney disease (CKD) compared with the general population (1) and, among patients at high CV risk, in those with a reduction of glomerular filtration rate (GFR) (2). This risk may be evident even with a mild reduction in renal function (2-4) or in the presence of microalbuminuria (5) and is 10-100-fold higher in patients with end stage kidney disease (ESKD) (6). In fact, patients in the early stages CKD are more likely to die from $\mathrm{CV}$ diseases than to progress to ESKD (7). These findings suggest that a reduced GFR is an independent $\mathrm{CV}$ risk factor. Since the prevalence of $\mathrm{CKD}$ in the general population is high and rising (8), this condition is a major public health problem.

Established CV risk factors, such as hypertension and diabetes mellitus, only explain part of the excessive $\mathrm{CV}$ risk reported in CKD patients (9). Therefore, other factors are likely to be involved. Carotid arteriosclerosis and atherosclerosis are increased in CKD, play a role in the causation of CV disease in CKD patients (10-12) and can also affect the progression of kidney disease (13-15). Possible mechanisms include functional and structural alterations of the arterial wall, including endothelial

$\wedge$ ORCID: 0000-0003-1678-3778. 
dysfunction, extracellular matrix stiffening, mesangial cell proliferation, low density lipoprotein (LDL)-dependent stimulation of fibronectin, mesangial matrix production and recruitment of inflammatory cells (16-19). Considering that myocardial disease [left ventricular hypertrophy (LVH), fibrosis and dysfunction] and not atheromatous coronary artery disease is the principal cause of $\mathrm{CV}$ death and disease in CKD (20), large elastic arteries arteriosclerosis could contribute to the effect of CKD on $\mathrm{CV}$ events.

The reduction in carotid-femoral pulse wave velocity, a measure of large elastic arteries stiffness, is associated with improved survival independent of blood pressure changes in patients with ESKD (21). Several treatment options have been proposed to improve carotid function in various clinical settings, including CKD (19); the early identification of patients with increased large elastic arteries stiffness could be useful to reduce the progression of CKD and the risk for $\mathrm{CV}$ events.

In this review we aimed to discuss the specific carotid phenotype of CKD, the different vascular involvement in carotid and muscular arteries, the effect of carotid stiffness on ventricular-vascular coupling and the mechanisms at the origin of the increased cardio- and cerebrovascular risk in CKD patients.

We present the following article in accordance with the Narrative Review checklist (available at http://dx.doi. org/10.21037/atm-20-5001).

\section{Methods}

A literature search of studies in humans was performed using MEDLINE, Scopus, ISI Web of Science, and Google Scholar databases (last accessed on 01 September 2020) without restrictions on the year of publication using the terms "carotid artery", "arterial stiffness", or "intimamedia thickness" in combination with "chronic kidney disease", "inflammation", or "hypertension". The inclusion criteria included peer-reviewed publications of randomized controlled trials, observational studies, reviews, metaanalyses and guidelines in English. First, the titles of these articles were screened for relevance. Second, publications with titles or abstracts appearing to meet the aims of this review were selected. The reference lists of the analyzed articles were also searched. These articles were subjected to the same selection procedures. We discuss both the findings and their relevance in the subsections below.

\section{Discussion}

\section{Carotid phenotype in CKD}

In patients with CKD, 2 distinct and partially overlapping alterations of the carotid arteries are detectable, atherosclerosis and arteriosclerosis. Atherosclerosis is a disease of conduit arteries with a patchy distribution, caused by lipid deposition in the intima layer of the arterial wall that leads to intima-media thickening and atherosclerotic plaque formation (22). In contrast, arteriosclerosis is caused by functional (i.e., endothelial dysfunction) and/ or structural alterations of the arterial wall (i.e., changes of the intrinsic characteristics of the biomaterial, thickening and calcification of the medial arterial layer). In patients with CKD, arterial remodeling seems to differently affect elastic (i.e., aorta and common carotid artery) and muscular arteries (i.e., brachial, femoral and renal artery).

\section{Carotid atherosclerosis in CKD}

Atherosclerosis is a progressive disease that includes subclinical lesions [increased carotid intima-media thickness (cIMT) (23)] and more advanced lesions (plaque and stenosis). The involvement of the carotid district is considered a proxy of systemic atherosclerosis (24).

Carotid plaque rupture or stenosis are two critical complications in the evolution of atherosclerotic plaque $(25,26)$. Plaque formation is characterized by the deposition of cholesterol in the intima layer. The further production of connective tissue by fibroblasts, and calcium deposition contribute to the sclerosis and hardening of the atherosclerotic lesions and reduction of the arterial calibre (27). In patients with $C K D$, further studies are needed to test whether alterations of the $\mathrm{Wnt} / \beta$-catenin signalling pathway is involved in the development of atherosclerotic lesions $(28,29)$. Moreover, atherosclerotic lesions can stimulate clot formation and thrombosis, with the consequent sudden obstruction of blood flow. Finally, plaque rupture can lead to the cholesterol crystal embolization syndrome $(30,31)$, a manifestation of atherosclerotic disease and a relatively rare complication of invasive arterial procedures, with important clinical manifestations ranging from peripheral cutaneous manifestations (e.g., livedo reticularis, blue toe syndrome) and renal failure to global neurologic deficits, depending on the arterial district involved. The changes in plaque composition, inflammation and geometry may 


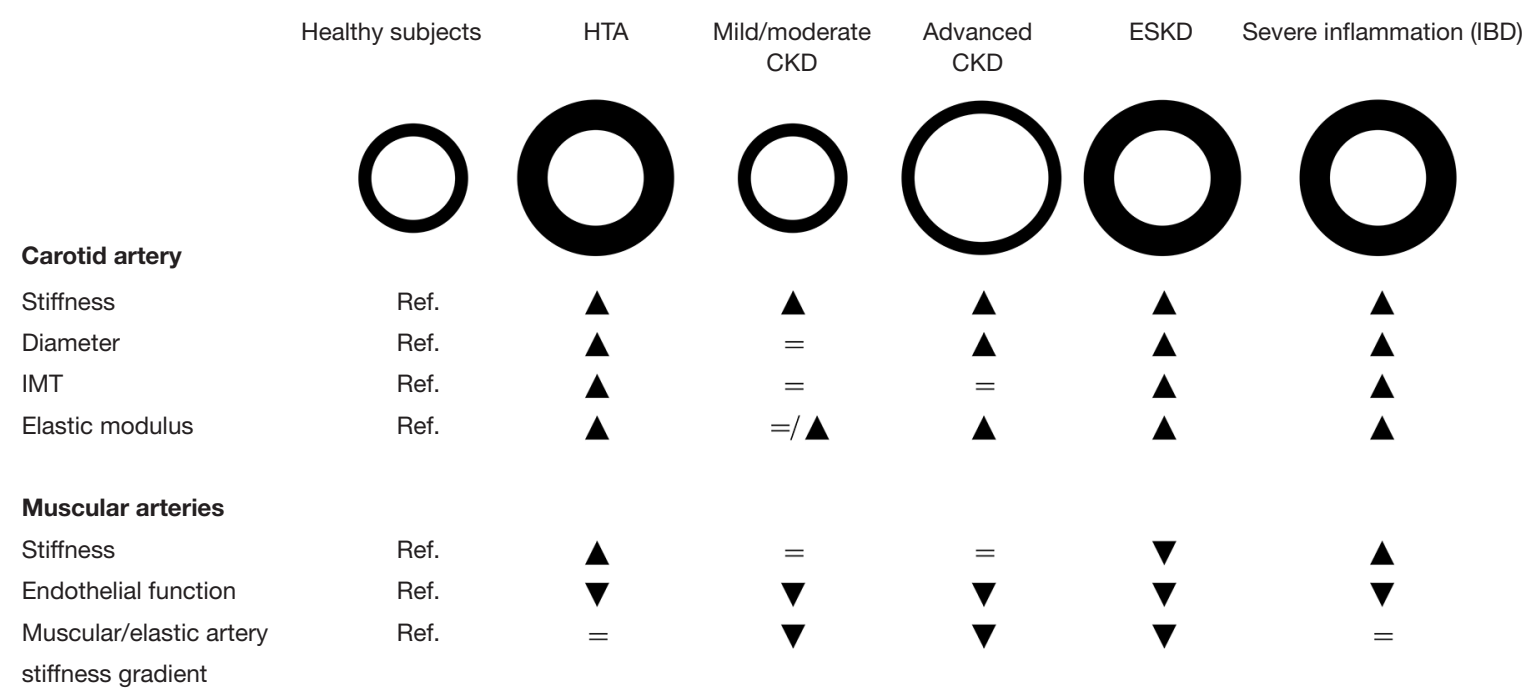

Figure 1 Arterial phenotypes. CKD, chronic kidney disease; ESKD, end-stage kidney disease; IBD, inflammatory bowel disease; IMT, intima-media thickness; HTA, hypertension; Ref., reference group (healthy state).

predispose to plaque rupture $(32,33)$. In this regard, the common carotid artery at the level of the plaque is stiffer than the adjacent segment (34). This may limit the strain of the whole arterial wall and increase the arterial wall stress, predisposing carotid plaques to a greater risk of rupture (35). Carotid remodelling is more evident at the level of the plaque since the stiffness and the mechanical properties of the common carotid artery measured in a section free of plaque is comparable to that observed in patients without carotid plaque (34). In patients with advanced CKD, the enlargement of the carotid artery (Figure 1) may contribute to the increased in arterial wall stress and risk of plaque rupture.

\section{From carotid atherosclerosis to CKD progression and $C V$ events}

Carotid atherosclerosis is associated with an increased $\mathrm{CV}$ risk in the general population $(36,37)$ and in patients with CKD (38-40). In particular, the risk for stroke is high in CKD patients with advanced atherosclerotic lesions (41) and increases according to the decline in renal function (42).

The link between carotid atherosclerosis and GFR, weak in patients with normal kidney function and in those with diabetes, increases in patients with CKD (43-48). However, it is difficult to dissect the role of CKD from the cluster of risk factors that may accompany carotid atherosclerosis (e.g., hypertension, diabetes, dyslipidaemia and inflammation) in these patients (49-51). In this context, qualitative and quantitative lipid abnormalities have been reported in these patients (52-55) and linked to both carotid atherosclerosis (55-58) and CKD progression (59). Moreover, blood pressure, haemoglobin and several mineral metabolism parameters predict carotid atherosclerosis progression in CKD patients $(60,61)$. Finally, the association between GFR and carotid atherosclerosis is greatly reduced or lost after adjustment for $\mathrm{CV}$ risk factors $(43,62)$ and it has been suggested that cIMT can even be comparable between patients with CKD and healthy controls (63). Accordingly, in a recent study, known vascular risk factors only explained a small proportion of variance in cIMT whereas the addition of GFR did not significantly contribute to the cIMT variance (64). Considered together, these studies suggest that the role of kidney dysfunction as an independent risk factor for carotid atherosclerosis should be better clarified.

\section{Carotid arteriosclerosis in CKD}

The increase of large elastic arteries stiffness, a vascular biomarker (24) and an independent CV risk predictor (65), is reported in patients with CKD $(63,66-68)$, even in those with a very mild reduction in GFR $\left(60-90 \mathrm{~mL} / \mathrm{min} / 1.73 \mathrm{~m}^{2}\right.$ without proteinuria) (69).

Several mechanisms are involved in the pathogenesis of carotid and aortic stiffening in CKD (19). Briefly, several uraemic toxins (i.e., hypercalcaemia, phosphates, 
increased levels of parathyroid hormone, uric acid, endothelin, advanced glycation end-products, and asymmetric dimethylarginine) are also vascular toxins. They may contribute, directly or through the development of endothelial dysfunction (70,71), inflammation (72), oxidative stress $(73,74)$, and vascular calcification $(75,76)$, to functional and/or structural arterial stiffening (19).

Functional alterations of the arterial wall could precede structural arterial stiffening in CKD since endothelial dysfunction is reported in participants with a mild reduction in GFR $(77,78)$ whereas the changes of the characteristics of the biomaterial and the outward remodeling (enlargement and thickening) of the arterial wall are evident in patients with advanced CKD and ESKD but not in early stages of CKD $(63,68,69)$. In this context, the enlargement of the carotid arterial wall is probably due to the inability of the arterial wall to sustain a repeated alternating deforming force and the consequent thinning and fragmentation of elastic fibers (elastic fatigue); qualitative and quantitative alterations of elastic fibers have been involved in the enlargement of the arterial wall in experimental CKD models $(79,80)$. Carotid thickening has been reported in patients with ESKD and in those with CKD and hypertension (81). In this regard, carotid thickening is considered a compensatory mechanism aimed at normalizing circumferential wall stress in the presence of dilatation or increased blood pressure. Therefore, considering that carotid enlargement precedes wall thickening (63), circumferential wall stress is increased in advanced CKD. Moreover, carotid plaque, carotid intimamedia thickness, and coronary calcification, known noninvasive measures of atherosclerosis, equally discriminate prevalent $\mathrm{CV}$ disease in patients with reduced renal function (82).

\section{Muscular elastic arteries stiffness in CKD}

In contrast to the carotid artery, the stiffness of brachial and femoral arteries is not increased and can be even reduced in patients with CKD $(83,84)$. In these patients, an inward remodeling (reduction of diameter) of the renal arteries has been also reported and associated with an increased risk of $\mathrm{CV}$ events $(85,86)$. The association between GFR and renal artery diameter was confirmed in patients with and without renal artery stenosis, and was age, sex, body surface area, diabetes, hypertension and smoking independent (85).

\section{Stiffness mismatch in CKD}

Physiologically, arterial stiffness is lower in the carotid and aorta, two central elastic arteries, than in peripheral muscular arteries in youth. However, central elastic arteries stiffness increases with aging whereas the stiffness of muscular arteries remains almost unchanged or increases to a lesser extent (87). The consequence of this differential effect of aging on muscular and elastic arteries is that the elastic/muscular arteries stiffness gradient is first equalized (elastic arteries stiffness $=$ muscular arteries stiffness), and then reversed (elastic arteries stiffness $>$ muscular arteries stiffness). This process is referred to as stiffness mismatch (88-90) and has important haemodynamic and clinical consequences since in youth the physiological stiffness gradient helps to reduce the transmission of the forward pressure wave into the microcirculation whereas with advancing age the increased carotid and aortic stiffness leads to the inversion of the stiffness gradient and causes an enhanced transmission of forward energy waves into the microcirculation. This may cause vascular damage (90), contributing to the pathogenesis of white matter lesions of the brain (91), renal dysfunction $(92,93)$ and, at least in patients with ESKD, increased mortality (94).

In contrast to what happens in other models of increased arterial stiffness (Figure 1), in patients with ESKD carotid and aortic stiffening can be accompanied by the reduction in stiffness of muscular arteries (94). This mechanism is useful to dampen the backward wave reflections and to mitigate the effects of increased central elastic arteries stiffness on central blood pressure; this is potentially cardioprotective. Moreover, the reduced stiffness of muscular arteries could help to smooth the forward waves and prevent an enhanced transmission of these waves to the microcirculation of target organs.

\section{Ventricular-vascular coupling in $C K$}

Physiologically, left ventricular (LV) function is coupled with arterial function to ensure maximum cardiac work and efficiency (95). The coupling ratio between arterial elastance $(\mathrm{Ea})$, a measure of ventricular afterload determined by the ratio of end-systolic pressure to stroke volume, and LV systolic elastance (Ees), a measure of ventricular stiffness at end systole determined by the ratio of end-systolic pressure to end-systolic volume (is generally $0.7-1.0$ ). Therefore, $\mathrm{LV}$ work efficiency is physiologically maximised. Ees falls 
in the presence of systolic dysfunction and increases in the presence of a stiff vascular system (increased $\mathrm{Ea}$ ), to maintain cardiac efficiency (Ea/Ees $=0.7-1.0)$ and to ensure a proper transfer of blood to the arterial tree without excessive changes in pressure. This compensatory mechanism is useful to maintain cardiac performance but leads to the reduction in cardiac reserve and diastolic function, haemodynamic instability and increased susceptibility to flash pulmonary oedema (95). In CKD, the increase of carotid and aortic stiffness leads to a parallel increase of LV stiffness (96). Therefore, considering that large elastic arteries stiffness is increased even in patients with a very mild reduction of GFR (60-90 $\mathrm{mL} / \mathrm{min} / 1.73 \mathrm{~m}^{2}$ without proteinuria) (69), the abnormalities of $\mathrm{LV}$ function could start early in patients with CKD. Further studies are needed to test this hypothesis in patients with a mild reduction of GFR.

\section{Vascular phenotypes in other models of increased arterial stiffness}

Carotid and aortic stiffness is increased in CKD, hypertension and several diseases characterized by a chronic severe inflammation, such as inflammatory bowel disease (IBD) and rheumatoid arthritis (RA) $(97,98)$. However, according to the different pathogenesis and clinical features, also the mechanisms involved in the arterial stiffening process and the arterial phenotypes may be different in these diseases (Figure 1).

\section{Arterial phenotype in hypertension}

The acute increase of blood pressure leads to an increase of carotid diameter and, consequently, circumferential wall stress and arterial stiffening. In patients with hypertension, the chronic increase of carotid diameter and circumferential wall stress leads to an adaptive increase of the arterial wall thickness (63). The consequence of this process is an increased carotid stiffness and outward remodeling (increased arterial diameter and thickness). The impact of high-normal blood pressure and hypertension on stenosis were more evident in subjects with CKD (99). Moreover, the elastic modulus, a measure of the elastic properties of the biomaterial of the arterial wall, of the carotid artery is increased in patients with hypertension (63). Therefore, considering that the stiffness of muscular arteries can also be increased in these patients, the muscular/elastic artery stiffness gradient can be comparable between controls and patients with hypertension (100).

\section{Arterial phenotype in patients with chronic severe inflammation}

The arterial phenotype of patients with CKD differs from that of patients with chronic severe inflammation (i.e., IBD and RA). Elastic artery stiffness is increased in patients with either chronic severe inflammation or CKD compared with their respective controls $(101,102)$. Interestingly, the stiffness of the brachial artery, a muscular artery, increases with aging in IBD but not in CKD (83) and is higher, (I) in IBD and RA patients than in matched healthy control subjects $(83,101)$, and, (II) in IBD patients than in CKD patients with a comparable stiffness of the aorta (83). Moreover, the stiffness of both muscular and elastic arteries is positively correlated with disease duration in IBD $(101,103)$. Considered together, these findings suggest that both elastic and muscular arteries stiffness could increase in patients with chronic severe inflammation; in support of this hypothesis, the vessel targets of inflammation (elastin, collagen and smooth muscle cells) can be found in both elastic and muscular arteries. Inversely, the increase of elastic arteries stiffness accompanied by the reduction of muscular arteries stiffness could be a feature of CKD.

\section{From large elastic artery stiffening to $C V$ events}

Physiologically, the arterial system has 2 important functions, the conduit and "cushioning" functions. The former is involved in the delivery of blood from the heart to peripheral tissues whereas the latter is involved in the dampening of the pulse wave during systole, achieving a continuous flow in peripheral blood vessels. In this regard, approximately $50 \%$ of the stroke volume is momentarily stored within large elastic arteries thanks to the elastic deformation of the arterial wall during systole and returned to the circulation by the discharge of the energy stored in the arterial wall during diastole (104). In the presence of stiffened arteries, the cushioning function of the carotid artery and aorta is altered and a larger part of the stroke volume is directly forwarded to the peripheral tissues during systole, leading to a rise in central systolic blood pressure (SBP) and a drop in central diastolic blood pressure (DBP). The rise of central SBP leads to a parallel increase in $\mathrm{LV}$ work and oxygen requirement and is involved in the development of $\mathrm{LVH}$, present in $>70 \%$ of patients with ESKD and detectable even in patients with early stages of CKD $(105,106)$; the drop of central DBP leads to decreased coronary artery perfusion pressure and is associated with an 
increased risk of myocardial ischaemia; finally, the increase of central pulse pressure leads to an increased risk of stroke. In patients with ESKD and renal transplant recipients, the increase of carotid stiffness is associated with an increased risk in all-cause mortality and CV events $(13,107)$.

\section{Increased carotid stiffness and baroreflex dysfunction}

Baroreflex dysfunction is reported in advanced CKD and ESKD and is associated with an increased risk of sudden death and all-cause mortality in hypertensive patients with ESKD (108). Baroreceptors are located within the arterial wall in the carotid bulb and are stretch-sensitive mechanoreceptors. Therefore, considering that the increase of large elastic arteries stiffness is associated with the drop in orthostatic SBP in stage 3-4 CKD patients (109), the impaired baroreflex function reported in patients with increased carotid stiffness (110) could be caused by the reduced stimulation of the baroreceptors rather than an alteration of the neural component of the baroreflex arc (111). Further studies are needed to test whether the neural component of the baroreflex arc is altered in patients with early stages $\mathrm{CKD}$, in whom an increased carotid stiffness is reported (69).

\section{Treatment options}

Several therapeutic options have been proposed to improve carotid function $(19,112)$. Statin therapy is useful to reduce the risk of $\mathrm{CV}$ events and contrast-induced acute kidney injury in patients with carotid artery disease (113-115) and in those with CKD (116-118). Statin therapy is useful to reduce also all-cause mortality, CV death, myocardial infarction and proteinuria in patients with CKD whereas has uncertain effects on stroke and CKD progression $(118,119)$. The use of statins may improve patient and graft survival after kidney transplantation (120). Moreover, in patients with severe carotid artery stenosis, statin pretreatment may decrease the periprocedural complications of carotid artery stenting (CAS) $(113,121)$ and carotid endarterectomy (CEA) (113). These benefits can be explained by the lipid lowering effect as well as the antiproliferative effect on smooth muscle cells, the stabilisation of atherosclerotic plaques, improvement of endothelial function and arterial stiffness, decreased oxidative stress and antithrombotic effect of statins (112). Interestingly, the effect of statins on cIMT could be reduced in patients with CKD (122), confirming that several mechanisms are involved in the thickening process of the carotid artery in these patients.

CEA and CAS are options for the management of severe carotid artery stenosis. In these patients, renal function should be evaluated with GFR rather than serum creatinine since the former measure was more sensitive in detecting perioperative stroke/death after CEA in patients with CKD (123). Moreover, CEA has shown promising results for stroke risk reduction in CKD patients with high-grade symptomatic carotid stenosis (124). In a National Inpatient Sample surveyed for CAS and CEA among CKD stage 3-5 and ESKD patients, although CAS was independently associated with in-hospital major adverse CV and cerebrovascular events (MACCE), propensity score matching showed no risk difference in MACCE between CAS and CEA (125). After intervention for carotid artery stenosis, stroke rate is low in patients with moderate-severe CKD whereas mortality increases with worsening renal function at 30-day (126); severe CKD is associated with cerebrovascular events or death at 1 and 5 years of follow-up $(126,127)$. Carotid revascularization in ESKD has been recently questioned since both CAS and CEA were associated with 4-fold higher odds of inhospital mortality (128). Moreover, considering that CAS requires the administration of contrast media, the risk of contrast-induced acute kidney injury should be considered (115) and CAS performed in selected symptomatic high-risk patients if CEA is not suitable (124). CAS in asymptomatic patients with severe renal dysfunction should be considered with caution since the risks of repair may outweigh the benefits in these patients $(129,130)$. Further treatments tested to improve carotid function include antihypertensive, anti-inflammatory and immunosuppressive drugs, renal transplantation and dialysis modalities (19). However, more large-scale and randomized trials are needed to confirm the efficacy of these treatment options in the reduction of $\mathrm{CV}$ events or delay of the progression of CKD. In this regard, only one trial, performed in 150 ESKD patients monitored for $51 \pm 38$ months, has demonstrated that the $\mathrm{CV}$ risk is reduced in those with improved arterial stiffness (21).

\section{Conclusions}

Carotid arteriosclerosis and atherosclerosis are reported in patients with CKD and are associated with poor outcome. The stiffening process of the carotid artery starts early, in patients with a mild reduction in GFR, whereas an outward remodeling is evident in more advanced stages of CKD. In 
muscular elastic arteries, a reduced stiffness is reported in patients with advanced CKD and an inward remodeling is evident during early stages of CKD. An increase in cIMT and plaque formation is evident in patients with advanced CKD. Contrast-induced acute kidney injury and kidney function, in general, deserve more attention from vascular surgeons.

\section{Acknowledgments}

Funding: None.

\section{Footnote}

Provenance and Peer Review: This article was commissioned by the Guest Editor (Kosmas I. Paraskevas) for the series "Carotid Artery Stenosis and Stroke - Prevention and Treatment Part II" published in Annals of Translational Medicine. The article has undergone external peer review.

Reporting Checklist: The authors have completed the Narrative Review reporting checklist. Available at http:// dx.doi.org/10.21037/atm-20-5001

Conflicts of Interest: Both authors have completed the ICMJE uniform disclosure form (available at http://dx.doi. org/10.21037/atm-20-5001). The series "Carotid Artery Stenosis and Stroke - Prevention and Treatment Part II" was commissioned by the editorial office without any funding or sponsorship. DPM has given talks, acted as a consultant or attended conferences sponsored by Amgen, Novo Nordisk and Libytec. The authors have no other conflicts of interest to declare.

Ethical Statement: The authors are accountable for all aspects of the work in ensuring that questions related to the accuracy or integrity of any part of the work are appropriately investigated and resolved.

Open Access Statement: This is an Open Access article distributed in accordance with the Creative Commons Attribution-NonCommercial-NoDerivs 4.0 International License (CC BY-NC-ND 4.0), which permits the noncommercial replication and distribution of the article with the strict proviso that no changes or edits are made and the original work is properly cited (including links to both the formal publication through the relevant DOI and the license). See: https://creativecommons.org/licenses/by-nc-nd/4.0/.

\section{References}

1. Go AS, Chertow GM, Fan D, et al. Chronic kidney disease and the risks of death, cardiovascular events, and hospitalization. N Engl J Med 2004;351:1296-305.

2. Capodanno D, Marcantoni C, Ministeri M, et al. Incorporating glomerular filtration rate or creatinine clearance by the modification of diet in renal disease equation or the Cockcroft-Gault equations to improve the global accuracy of the Age, Creatinine, Ejection Fraction $[\mathrm{ACEF}]$ score in patients undergoing percutaneous coronary intervention. Int J Cardiol 2013;168:396-402 .

3. Matsushita K, van der Velde M, Astor BC, et al. Association of estimated glomerular filtration rate and albuminuria with all-cause and cardiovascular mortality in general population cohorts: a collaborative meta-analysis. Lancet 2010;375:2073-81.

4. Van Biesen W, De Bacquer D, Verbeke F, et al. The glomerular filtration rate in an apparently healthy population and its relation with cardiovascular mortality during 10 years. Eur Heart J 2007;28:478-83.

5. Williams B, Mancia G, Spiering W, et al. 2018 ESC/ESH Guidelines for the management of arterial hypertension. Eur Heart J 2018;39:3021-104.

6. Foley RN, Parfrey PS, Sarnak MJ. Clinical epidemiology of cardiovascular disease in chronic renal disease. Am J Kidney Dis 1998;32:S112-9.

7. Dalrymple LS, Katz R, Kestenbaum B, et al. Chronic kidney disease and the risk of end-stage renal disease versus death. J Gen Intern Med 2011;26:379-85.

8. Coresh J, Selvin E, Stevens LA, et al. Prevalence of chronic kidney disease in the United States. JAMA 2007;298:2038-47.

9. Coresh J, Longenecker JC, Miller ER III, et al. Epidemiology of cardiovascular risk factors in chronic renal disease. J Am Soc Nephrol 1998;9:S24-S30.

10. Blacher J, Pannier B, Guerin AP, et al. Carotid arterial stiffness as a predictor of cardiovascular and all-cause mortality in end-stage renal disease. Hypertension 1998;32:570-4.

11. Granata A, Clementi A, Virzì GM, et al. Cardiorenal syndrome type 4: From chronic kidney disease to cardiovascular impairment. Eur J Intern Med 2016;30:1-6.

12. Zoungas S, Cameron JD, Kerr PG, et al. Association of carotid intima-medial thickness and indices of arterial stiffness with cardiovascular disease outcomes in CKD. Am J Kidney Dis 2007;50:622-30.

13. Briet M, Collin C, Karras A, et al. Arterial remodeling 
associates with CKD progression. J Am Soc Nephrol 2011;22:967-74.

14. Sedaghat S, Mattace-Raso FUS, Hoorn EJ, et al. Arterial Stiffness and Decline in Kidney Function. Clin J Am Soc Nephrol 2015;10:2190-7.

15. Shimizu M, Furusyo N, Mitsumoto F, et al. Subclinical carotid atherosclerosis and triglycerides predict the incidence of chronic kidney disease in the Japanese general population: results from the Kyushu and Okinawa Population Study (KOPS). Atherosclerosis 2015;238:207-12.

16. Takemura T, Yoshioka K, Aya N, et al. Apolipoproteins and lipoprotein receptors in glomeruli in human kidney diseases. Kidney Int 1993;43:918-27.

17. Nishida Y, Yorioka N, Oda H, et al. Effect of lipoproteins on cultured human mesangial cells. Am J Kidney Dis 1997;29:919-30.

18. Rovin BH, Tan LC. LDL stimulates mesangial fibronectin production and chemoattractant expression. Kidney Int 1993;43:218-25.

19. Zanoli L, Lentini P, Briet M, et al. Arterial Stiffness in the Heart Disease of CKD. J Am Soc Nephrol 2019;30:918-28.

20. Moody WE, Edwards NC, Chue CD, et al. Arterial disease in chronic kidney disease. Heart 2013;99:365-72.

21. Guerin AP, Blacher J, Pannier B, et al. Impact of aortic stiffness attenuation on survival of patients in end-stage renal failure. Circulation 2001;103:987-92.

22. Lusis AJ. Atherosclerosis. Nature 2000;407:233-41.

23. Sakamoto A, Torii S, Jinnouchi H, et al. Pathologic intimal thickening: Are we any closer to understand early transitional plaques that lead to symptomatic disease? Atherosclerosis 2018;274:227-9.

24. Vlachopoulos C, Xaplanteris P, Aboyans V, et al. The role of vascular biomarkers for primary and secondary prevention. A position paper from the European Society of Cardiology Working Group on peripheral circulation: Endorsed by the Association for Research into Arterial Structure and Physiology (ARTERY) Society. Atherosclerosis 2015;241:507-32.

25. Naghavi M, Libby P, Falk E, et al. From vulnerable plaque to vulnerable patients. A call for new definitions and risk assessment strategies. Part I. Circulation 2003;108:1664-72.

26. Kelly DM, Rothwell PM. Prevention and treatment of stroke in patients with chronic kidney disease: an overview of evidence and current guidelines. Kidney Int 2020;97:266-78.
27. Rafieian-Kopaei M, Setorki M, Doudi M, et al. Atherosclerosis: process, indicators, risk factors and new hopes. Int J Prev Med 2014;5:927-46.

28. Bouquegneau A, Evenepoel P, Paquot F, et al. Sclerostin Within the Chronic Kidney Disease Spectrum. Clin Chim Acta 2020;502:84-90.

29. Gaudio A, Fiore V, Rapisarda R, et al. Sclerostin is a possible candidate marker of arterial stiffness: Results from a cohort study in Catania. Mol Med Rep 2017;15:3420-4.

30. Paraskevas KI, Koutsias S, Mikhailidis DP, et al. Cholesterol crystal embolization: a possible complication of peripheral endovascular interventions. J Endovasc Ther 2008;15:614-25.

31. Li X, Bayliss G, Zhuang S. Cholesterol Crystal Embolism and Chronic Kidney Disease. Int J Mol Sci 2017;18:1120.

32. Richardson PD, Davies MJ, Born GV. Influence of plaque configuration and stress distribution on fissuring of coronary atherosclerotic plaques. Lancet 1989;2:941-4.

33. Versluis A, Bank A, Douglas WH. Fatigue and plaque rupture in myocardial infarction. J Biomech 2006;39:339-47.

34. Paini A, Boutouyrie P, Calvet D, et al. Multiaxial mechanical characteristics of carotid plaque: analysis by multiarray echotracking system. Stroke 2007;38:117-23.

35. Beaussier H, Masson I, Collin C, et al. Carotid plaque, arterial stiffness gradient, and remodeling in hypertension. Hypertension 2008;52:729-36.

36. Bots ML, Hoes AW, Koudstaal PJ, et al. Common carotid intima-media thickness and risk of stroke and myocardial infarction: the Rotterdam Study. Circulation 1997;96:1432-7.

37. Hodis HN, Mack WJ, LaBree L, et al. The role of carotid arterial intima-media thickness in predicting clinical coronary events. Ann Intern Med 1998;128:262-9.

38. Benedetto FA, Mallamaci F, Tripepi G, et al. Prognostic value of ultrasonographic measurement of carotid intima media thickness in dialysis patients. J Am Soc Nephrol 2001;12:2458-64.

39. Kajitani N, Uchida HA, Suminoe I, et al. Chronic kidney disease is associated with carotid atherosclerosis and symptomatic ischaemic stroke. J Int Med Res 2018;46:3873-83.

40. Valdivielso JM, Betriu A, Martinez-Alonso M, et al. Factors predicting cardiovascular events in chronic kidney disease patients. Role of subclinical atheromatosis extent assessed by vascular ultrasound. PLoS One 2017;12:e0186665.

41. Mathew A, Eliasziw M, Devereaux PJ, et al. Carotid endarterectomy benefits patients with CKD and symptomatic high-grade stenosis. J Am Soc Nephrol 
2010;21:145-52.

42. Lee M, Saver JL, Chang KH, et al. Low glomerular filtration rate and risk of stroke: meta-analysis. BMJ 2010;341:c4249.

43. Han L, Bai X, Lin H, et al. Lack of independent relationship between age-related kidney function decline and carotid intima-media thickness in a healthy Chinese population. Nephrol Dial Transplant 2010;25:1859-65.

44. Kastarinen H, Ukkola O, Kesaniemi YA. Glomerular filtration rate is related to carotid intima-media thickness in middle-aged adults. Nephrol Dial Transplant 2009;24:2767-72.

45. Wu Y, Hou J, Li J, et al. Correlation between Carotid Intima-Media Thickness and Early-Stage Chronic Kidney Disease: Results from Asymptomatic Polyvascular Abnormalities in Community Study. J Stroke Cerebrovasc Dis 2016;25:259-65.

46. Yu FP, Zhao YC, Gu B, et al. Chronic Kidney Disease and Carotid Atherosclerosis in Patients With Acute Stroke. Neurologist 2015;20:23-6.

47. Leskinen Y, Lehtimaki T, Loimaala A, et al. Carotid atherosclerosis in chronic renal failure-the central role of increased plaque burden. Atherosclerosis 2003;171:295-302.

48. Nakade Y, Toyama T, Furuichi K, et al. Impact of kidney function and urinary protein excretion on intima-media thickness in Japanese patients with type 2 diabetes. Clin Exp Nephrol 2015;19:909-17.

49. Paraskevas KI, Veith FJ, Eckstein HH, Ricco JB, Mikhailidis DP. Cholesterol, carotid artery disease and stroke: what the vascular specialist needs to know. Ann Transl Med 2020;8:1265.

50. Katsiki N, Mikhailidis DP. Diabetes and carotid artery disease: a narrative review. Ann Transl Med 2020;8:1280.

51. Marcucci M, Franchi C, Nobili A, et al. Defining Aging Phenotypes and Related Outcomes: Clues to Recognize Frailty in Hospitalized Older Patients. J Gerontol A Biol Sci Med Sci 2017;72:395-402.

52. Bagdade JD, Porte D Jr, Bierman EL. Hypertriglyceridemia. A metabolic consequence of chronic renal failure. N Engl J Med 1968;279:181-5.

53. Mikolasevic I, Žutelija M, Mavrinac V, et al. Dyslipidemia in patients with chronic kidney disease: etiology and management. Int J Nephrol Renovasc Dis 2017;10:35-45.

54. Kwan BCH, Kronenberg F, Beddhu S, et al. Lipoprotein Metabolism and lipid management in chronic kidney disease. J Am Soc Nephrol 2007;18:1246-61.

55. Filler G, Taheri S, McIntyre C, et al. Chronic kidney disease stage affects small, dense low-density lipoprotein but not glycated low-density lipoprotein in younger chronic kidney disease patients: a cross-sectional study. Clin Kidney J 2018;11:383-8.

56. Shoji T, Hatsuda S, Tsuchikura S, et al. Small dense lowdensity lipoprotein cholesterol concentration and carotid atherosclerosis. Atherosclerosis 2009;202:582-8.

57. Nasri H, Baradaran A. Association of serum lipoprotein(a) with ultrasonographically determined early atherosclerotic changes in the carotid and femoral arteries in kidney transplanted patients. Transplant Proc 2004;36:2683-6.

58. Khandelwal P, Murugan V, Hari S, et al. Dyslipidemia, carotid intima-media thickness and endothelial dysfunction in children with chronic kidney disease. Pediatr Nephrol 2016;31:1313-20.

59. Fried LF, Orchard TJ, Kasiske BL. Effect of lipid reduction on the progression of renal disease: a metaanalysis. Kidney Int 2001;59:260-9.

60. Abajo M, Betriu À, Arroyo D, et al. Mineral metabolism factors predict accelerated progression of common carotid intima-media thickness in chronic kidney disease: the NEFRONA study. Nephrol Dial Transplant 2017;32:1882-91.

61. Mudi A, Holland Z, Dickens C, et al. Factors associated with carotid intima media thickness in South African children with chronic kidney disease. Clin Nephrol 2019;92:250-7.

62. Bui AL, Katz R, Kestenbaum B, et al. Cystatin C and carotid intima-media thickness in asymptomatic adults: the Multi-Ethnic Study of Atherosclerosis (MESA). Am J Kidney Dis 2009;53:389-98.

63. Briet M, Bozec E, Laurent S, et al. Arterial stiffness and enlargement in mild-to-moderate chronic kidney disease. Kidney Int 2006;69:350-7.

64. Rundek T, Blanton SH, Bartels S, et al. Traditional risk factors are not major contributors to the variance in carotid intima-media thickness. Stroke 2013;44:2101-8.

65. Ben-Shlomo Y, Spears M, Boustred C, et al. Aortic pulse wave velocity improves cardiovascular event prediction: an individual participant meta-analysis of prospective observational data from 17635 subjects. J Am Coll Cardiol 2014;63:636-46.

66. Barenbrock M, Spieker C, Laske V, et al. Studies of the vessel wall properties in hemodialysis patients. Kidney Int 1994;45:1397-400.

67. London GM, Marchais SJ, Safar ME, et al. Aortic and large artery compliance in end-stage renal failure. Kidney Int 1990;37:137-42.

68. London GM, Guerin AP, Marchais SJ, et al. Cardiac and 
arterial interactions in end-stage renal disease. Kidney Int 1996;50:600-8.

69. Zanoli L, Empana JP, Perier MC, et al. Increased carotid stiffness and remodelling at early stages of chronic kidney disease. J Hypertens 2019;37:1176-82.

70. Morris ST, McMurray JJ, Rodger RS, et al. Impaired endothelium-dependent vasodilatation in uraemia. Nephrol Dial Transplant 2000;15:1194-200.

71. Klahr S. The role of nitric oxide in hypertension and renal disease progression. Nephrol Dial Transplant 2001;16:60-2.

72. Zoccali C, Mallamaci F, Tripepi G. Inflammatory proteins as predictors of cardiovascular disease in patients with end-stage renal disease. Nephrol Dial Transplant 2004;19:V67-V72.

73. Cai H, Harrison DG. Endothelial dysfunction in cardiovascular diseases: the role of oxidant stress. Circ Res 2000;87:840-4.

74. Modlinger PS, Wilcox CS, Aslam S. Nitric oxide, oxidative stress, and progression of chronic renal failure. Semin Nephrol 2004;24:354-65.

75. Demer LL, Tintut Y, Parhami F. Novel mechanisms in accelerated vascular calcification in renal disease patients. Curr Opin Nephrol Hypertens 2002;11:437-43.

76. Savage T, Clarke AL, Giles M, et al. Calcified plaque is common in the carotid and femoral arteries of dialysis patients without clinical vascular disease. Nephrol Dial Transplant 1998;13:2004-12.

77. Stam F, van Guldener C, Becker A, et al. Endothelial dysfunction contributes to renal function-associated cardiovascular mortality in a population with mild renal insufficiency: the Hoorn study. J Am Soc Nephrol 2006; 17:537-45.

78. Perticone F, Maio R, Tripepi G, et al. Endothelial dysfunction and mild renal insufficiency in essential hypertension. Circulation 2004;110:821-5.

79. Yamamoto Y, Sakata N, Meng J, et al. Possible involvement of increased glycoxidation and lipid peroxidation of elastin in atherogenesis in haemodialysis patients. Nephrol Dial Transplant 2002;17:630-6.

80. Amann K, Wolf B, Nichols C, et al. Aortic changes in experimental renal failure: hyperplasia or hypertrophy of smooth muscle cells? Hypertension 1997;29:770-5.

81. Ohara T, Kokubo Y, Toyoda K, et al. Impact of chronic kidney disease on carotid atherosclerosis according to blood pressure category: the Suita study. Stroke 2013;44:3537-9.

82. Adeseun GA, Xie D, Wang X, et al. Carotid plaque, carotid intima-media thickness, and coronary calcification equally discriminate prevalent cardiovascular disease in kidney disease. Am J Nephrol 2012;36:342-7.

83. Zanoli L, Lentini P, Boutouyrie P, et al. Pulse wave velocity differs between ulcerative colitis and chronic kidney disease. Eur J Intern Med 2018;47:36-42.

84. Kim ED, Tanaka H, Ballew SH, et al. Associations between kidney disease measures and regional pulse wave velocity in a large community-based cohort: The Atherosclerosis Risk in Communities (ARIC) study. Am J Kidney Dis 2018;72:682-90.

85. Zanoli L, Rastelli S, Marcantoni C, et al. Renal artery diameter, renal function and resistant hypertension in patients with low-to-moderate renal artery stenosis. J Hypertens 2012;30:600-7.

86. Zanoli L, Rastelli S, Marcantoni C, et al. Nonhemodynamically significant renal artery stenosis predicts cardiovascular events in persons with ischemic heart disease. Am J Nephrol 2014;40:468-77.

87. van der Heijden-Spek JJ, Staessen JA, Fagard RH, et al. Effect of age on brachial artery wall properties differs from the aorta and is gender dependent: a population study. Hypertension 2000;35:637-42.

88. McEniery CM, Yasmin, Hall IR, et al. Normal vascular aging: differential effects on wave reflection and aortic pulse wave velocity: the Anglo-Cardiff Collaborative Trial (ACCT). J Am Coll Cardiol 2005;46:1753-60.

89. Mitchell GF, Wang N, Palmisano JN, et al. Hemodynamic correlates of blood pressure across the adult age spectrum: noninvasive evaluation in the Framingham Heart Study. Circulation 2010;122:1379-86.

90. Mitchell GF, Parise H, Benjamin EJ, et al. Changes in arterial stiffness and wave reflection with advancing age in healthy men and women: the Framingham Heart Study. Hypertension 2004;43:1239-45.

91. Liao D, Cooper L, Cai J, et al. The prevalence and severity of white matter lesions, their relationship with age, ethnicity, gender, and cardiovascular disease risk factors: the ARIC Study. Neuroepidemiology 1997;16:149-62 .

92. Safar ME, London GM, Plante GE. Arterial stiffness and kidney function. Hypertension 2004;43:163-8.

93. Mitchell GF. Increased aortic stiffness: an unfavorable cardiorenal connection. Hypertension 2004;43:151-3.

94. Fortier C, Mac-Way F, Desmeules S, et al. Aortic-brachial stiffness mismatch and mortality in dialysis population. Hypertension 2015;65:378-84.

95. Chen CH, Nakayama M, Nevo E, et al. Coupled systolicventricular and vascular stiffening with age: implications 
for pressure regulation and cardiac reserve in the elderly. J Am Coll Cardiol 1998;32:1221-7.

96. Edwards NC, Ferro CJ, Townend JN, et al. Aortic distensibility and arterial-ventricular coupling in early chronic kidney disease: a pattern resembling heart failure with preserved ejection fraction. Heart 2008;94:1038-43.

97. Zanoli L, Briet M, Empana JP, et al. Vascular consequences of inflammation: a position statement from the ESH Working Group on Vascular Structure and Function and the ARTERY Society. J Hypertens 2020;38:1682-98.

98. Zanoli L, Mikhailidis DP, Bruno RM, et al. Aortic Stiffening Is an Extraintestinal Manifestation of Inflammatory Bowel Disease: Review of the Literature and Expert Panel Statement. Angiology 2020;71:689-97.

99. Kokubo Y. Carotid atherosclerosis in kidney disease. Contrib Nephrol 2013;179:35-41.

100.London GM, Pannier B, Safar ME. Arterial Stiffness Gradient, Systemic Reflection Coefficient, and Pulsatile Pressure Wave Transmission in Essential Hypertension. Hypertension 2019;74:1366-72.

101.Zanoli L, Boutouyrie P, Fatuzzo P, et al. Inflammation and Aortic Stiffness: An Individual Participant Data MetaAnalysis in Patients With Inflammatory Bowel Disease. J Am Heart Assoc 2017;6:e007003.

102. Ambrosino P, Tasso M, Lupoli R, et al. Non-invasive assessment of arterial stiffness in patients with rheumatoid arthritis: a systematic review and meta-analysis of literature studies. Ann Med 2015;47:457-67.

103.Zanoli L, Cannavò M, Rastelli S, et al. Arterial stiffness is increased in patients with inflammatory bowel disease. J Hypertens 2012;30:1775-81.

104. Briet M, Boutouyrie P, Laurent S, London GM. Arterial stiffness and pulse pressure in CKD and ESRD. Kidney Int 2012;82:388-400.

105. Stewart GA, Gansevoort RT, Mark PB, et al. Electrocardiographic abnormalities and uremic cardiomyopathy. Kidney Int 2005;67:217-26.

106. Mark PB, Johnston N, Groenning BA, et al. Redefinition of uremic cardiomyopathy by contrast-enhanced cardiac magnetic resonance imaging. Kidney Int 2006;69:1839-45.

107. Barenbrock M, Kosch M, Jöster E, et al. Reduced arterial distensibility is a predictor of cardiovascular disease in patients after renal transplantation. J Hypertens 2002;20:79-84.

108. Johansson M, Gao SA, Friberg P, et al. Baroreflex effectiveness index and baroreflex sensitivity predict allcause mortality and sudden death in hypertensive patients with chronic renal failure. J Hypertens 2007;25:163-8.

109. Kirkham FA, Rankin P, Parekh N, et al. Aortic stiffness and central systolic pressure are associated with ambulatory orthostatic BP fall in chronic kidney disease. J Nephrol 2020;33:317-24.

110. Mattace-Raso FU, van den Meiracker AH, Bos WJ, et al. Arterial stiffness, cardiovagal baroreflex sensitivity and postural blood pressure changes in older adults: The Rotterdam Study. J Hypertens 2007;25:1421-6.

111.Zanoli L, Empana JP, Estrugo N, et al. The neural baroreflex pathway in subjects with metabolic syndrome: A sub-study of the Paris prospective study III. Medicine (Baltimore) 2016;95:e2472.

112. Tsiara S, Elisaf M, Mikhailidis DP. Early vascular benefits of statin therapy. Curr Med Res Opin 2003;19:540-56.

113. Katsiki N, Triposkiadis F, Giannoukas AD, et al. Statin loading in cardiovascular surgery: never too early to treat. Curr Opin Cardiol 2018;33:436-43.

114. Naylor AR, Ricco JB, de Borst GJ, et al. Editor's Choice - Management of Atherosclerotic Carotid and Vertebral Artery Disease: 2017 Clinical Practice Guidelines of the European Society for Vascular Surgery (ESVS). Eur J Vasc Endovasc Surg 2018;55:3-81.

115.Paraskevas KI, Mikhailidis DP. Contrast-Induced Acute Kidney Injury in Patients Undergoing Carotid Artery Stenting: An Underestimated Issue. Angiology 2017;68:752-6.

116.Hwang SD, Kim K, Kim YJ, et al. Effect of statins on cardiovascular complications in chronic kidney disease patients: A network meta-analysis. Medicine (Baltimore) 2020;99:e20061.

117.Zhang J, Guo Y, Jin Q, et al. Meta-analysis of rosuvastatin efficacy in prevention of contrast-induced acute kidney injury. Drug Des Devel Ther 2018;12:3685-90.

118. Palmer SC, Navaneethan SD, Craig JC, et al. HMG CoA reductase inhibitors (statins) for people with chronic kidney disease not requiring dialysis. Cochrane Database Syst Rev 2014;(5):CD007784.

119. Su X, Zhang L, Lv J, et al. Effect of Statins on Kidney Disease Outcomes: A Systematic Review and Metaanalysis. Am J Kidney Dis 2016;67:881-92.

120. Rostami Z, Moteshaker Arani M, Salesi M, et al. Effect of Statins on Patients and Graft Survival in Kidney Transplant Recipients: a Survival Meta-analysis. Iran J Kidney Dis 2017;11:329-38.

121.Hong JH, Sohn SI, Kwak J, et al. Dose-dependent effect of statin pretreatment on preventing the periprocedural complications of carotid artery stenting. Stroke 
2017;48:1890-4.

122. Fathi R, Isbel N, Short L, et al. The effect of long-term aggressive lipid lowering on ischemic and atherosclerotic burden in patients with chronic kidney disease. Am J Kidney Dis 2004;43:45-52.

123. AbuRahma AF, Srivastava M, Chong B, et al. Impact of chronic renal insufficiency using serum creatinine vs glomerular filtration rate on perioperative clinical outcomes of carotid endarterectomy. J Am Coll Surg 2013;216:525-32.

124. Bilha SC, Burlacu A, Siriopol D, et al. Primary Prevention of Stroke in Chronic Kidney Disease Patients: A Scientific Update. Cerebrovasc Dis 2018;45:33-41.

125.Lima FV, Yen TY, Butler J, et al. Impact of chronic kidney disease in patients undergoing percutaneous or surgical carotid artery revascularization: Insights of the healthcare cost and utilization Project's National Inpatient Sample. Cardiovasc Revasc Med 2016;17:560-5.

Cite this article as: Zanoli L, Mikhailidis DP. Narrative Review of Carotid disease and the kidney. Ann Transl Med 2021;9(14):1210. doi: 10.21037/atm-20-5001
126. Klarin D, Lancaster RT, Ergul E, et al. Perioperative and long-term impact of chronic kidney disease on carotid artery interventions. J Vasc Surg 2016;64:1295-302.

127. Avgerinos ED, Go C, Ling J, et al. Survival and long-term cardiovascular outcomes after carotid endarterectomy in patients with chronic renal insufficiency. Ann Vasc Surg 2015;29:15-21.

128. Adil MM, Saeed F, Chaudhary SA, et al. Comparative Outcomes of Carotid Artery Stent Placement and Carotid Endarterectomy in Patients with Chronic Kidney Disease and End-Stage Renal Disease. J Stroke Cerebrovasc Dis 2016;25:1721-7.

129. Nathan DP, Tang GL. The impact of chronic renal insufficiency on vascular surgery patient outcomes. Semin Vasc Surg 2014;27:162-9.

130. Yuo TH, Sidaoui J, Marone LK, et al. Revascularization of asymptomatic carotid stenosis is not appropriate in patients on dialysis. J Vasc Surg 2015;61:670-4. 